\title{
CICLAGEM DE NUTRIENTES NUMA FLORESTA URBANA NO MUNICÍPIO DE SÃO PAULO, SP
}

\author{
Maurício Lamano Ferreira ${ }^{1}$
}

\author{
Edna Elisa Pereira ${ }^{2}$
}

Patrícia Monteiro ${ }^{3}$

\begin{abstract}
RESUMO
As florestas urbanas desempenham importante papel na dinâmica da comunidade em áreas urbanas. Além disto, estas áreas verdes são importantes componentes da paisagem que atenuam os efeitos da poluição atmosférica e sonora. Sendo assim, este trabalho teve por objetivo avaliar a ciclagem de nutrientes na interação solo-planta num fragmento de uma floresta urbana Atlântica. A área de estudo foi delimitada em uma parcela de $50 \mathrm{~m} \mathrm{X} 100 \mathrm{~m}$, onde foram distribuídos, para a análise de serapilheira, 40 coletores (litter traps) medindo $55 \mathrm{~cm}$ de diâmetro e 30 sacolas de decomposição (litter bags). Amostras de solos foram coletadas por meio de trincheiras estabelecidas na área. $\mathrm{O}$ material de serapilheira e as amostras de solo foram analisadas quimicamente quanto ao conteúdo nutricional. Observou-se que a produção de serapilheira foi maior em outubro. A taxa de decomposição se mostrou mais acentuada nos primeiros meses de exposição do material. A contribuição nutricional apresentou-se dentro dos padrões encontrados na literatura no que se refere a florestas tropicais. Em relação aos solos, os resultados obtidos mostraram uma grande disponibilidade de todos os elementos minerais estudados na camada $0-10 \mathrm{~cm}$. A relação entre os nutrientes indicou rápida taxa de decomposição no sítio de estudo. Sugere-se que o solo estudado apresenta uma alta taxa de decomposição, pois a ciclagem desses nutrientes está ocorrendo de forma rápida e eficiente para a manutenção da floresta.
\end{abstract}

PALAVRAS-CHAVE: Mata Atlântica, Parque Ecológico Guarapiranga, Ciclagem de nutrientes, Solo.

\section{NUTRIENT CYCLING IN A URBAN FOREST OF SÃO PAULO CITY, $S P$}

\begin{abstract}
Urban forests play an important role in the dynamics of the community in urban areas. Moreover, these green areas are important components of the landscape that mitigate the effects of air and sound pollution. Thus, this study aimed to assess nutrient cycling in the soil-plant interaction in an urban Atlantic forest fragment. The study area was bounded on a plot of $50 \mathrm{~m} \times 100 \mathrm{~m}$, where 40 collectors measuring $55 \mathrm{~cm}$ diameter were allocated for the analysis of litterfall production (litter traps) and 30 litter bags were used to assess the decomposition (litter bags). Soil samples were collected by means of trenches established in the area. The litterfall and soil samples were chemically analyzed according to their nutritional content. It was found that the litterfall production was higher in October. The decomposition rate was more pronounced in the first months of exposure of the material. The nutritional contribution was in accordance to the pattern found in the literature regarding the tropical

\footnotetext{
${ }^{1}$ Biólogo, Universidade Nove de Julho, Professor de ecologia. E-mail. mauecologia@yahoo.com.br

2 Bióloga, SYNGENTA, Pesquisadora. E-mail. edna.pereira@syngenta.com

3 Bióloga, Universidade Nove de Julho, ex-aluna de graduação. E-mail. curands@hotmail.com
} 


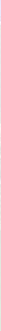

forests. Regarding soils, the results showed a large availability of all mineral elements studied in the 0$10 \mathrm{~cm}$ layer. The relationship between the nutrients indicated rapid rate of decomposition in the study site. It is suggested that the studied soil has a high rate of decomposition, because the cycling of these nutrients is occurring quickly and efficiently to maintain the forest.

KEY-WORDS: Atlantic forest, Guarapiranga Ecological Park, Nutrient cycling, Soil.

\title{
CICLO DE NUTRIENTES DE UN BOSQUE URBANO EN LA CIUDAD DE SÃO PAULO, SP
}

\begin{abstract}
RESUMEN
Los bosques urbanos desempeñan un papel importante en la dinámica de la comunidad en las zonas urbanas. Por otra parte, estas áreas verdes son componentes importantes del paisaje para mitigar los efectos de la contaminación del aire y sonido. Así, este estudio tuvo como objetivo evaluar el ciclo de nutrientes en la interacción suelo-planta en un fragmento de Mata Atlántica urbano. El área de estudio estaba limitado en una parcela de $50 \mathrm{~m} \times 100 \mathrm{~m}$, donde se distribuyeron 40 colectores, de $55 \mathrm{~cm}$ de diámetro y 30 bolsas de descomposición. Las muestras de suelo se recogieron por medio de trincheras establecidas en la zona. El material de las muestras de hojarasca y el suelo fueron analizadas químicamente en función de su contenido nutricional. Se encontró que la producción de hojarasca fue mayor en octubre. La velocidad de descomposición fue más pronunciada en los primeros meses de la exposición del material. El aporte nutricional se produjo en los patrones encontrados en la literatura en relación con los bosques tropicales. En cuanto a los suelos, los resultados mostraron una gran disponibilidad de todos los elementos minerales estudiados en la capa de 0-10 cm. La relación entre los nutrientes indicó rápida velocidad de descomposición en el sitio de estudio. Se sugiere que el suelo estudiado tiene una alta tasa de descomposición, debido a que el ciclo de estos nutrientes se está produciendo de forma rápida y eficiente para mantener el bosque.
\end{abstract}

PALABRAS CLAVE: Bosque Atlántico, Parque Ecológico del Guarapiranga, ciclo de nutrientes Suelo.

\section{INTRODUÇÃO}

Dentre as diversas atividades humanas que causam diminuição da biodiversidade o desenvolvimento urbano é responsável pelas maiores taxas de extinções locais devido à eliminação de espécies locais nativas (MARZLUFF, 2001). Assim, as florestas urbanas desempenham papel fundamental na construção de cidades sustentáveis por interferir diretamente na manutenção do habitat para diversas espécies de animais, plantas e fungos, além de trazer para as cidades um maior conforto térmico e promover a atenuação da poluição sonora e atmosférica. No entanto, poucos trabalhos visam a compreensão de alguns atributos ecológicos destas áreas verdes (BOLUND, HUNHAMMAR, 1999; PICKETT et al., 2001), priorizando assim aspectos ligados a percepção ambiental (OLIVEIRA et al., 2013) ou atributos paisagísticos. 


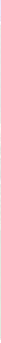

Ao longo do domínio Atlântico, os fragmentos de Mata Atlântica restantes apresentam-se em diversas formas, tamanhos, estádios de sucessão e situação de conservação (RIBEIRO et al., 2009). Numa visão geral, a floresta Atlântica pode ser vista como um mosaico diversificado de ecossistemas, mostrando estruturas e composições florísticas diversas, por conta de diferenças no solo, relevo, características climáticas ou processo de antropização existentes em toda a área de ocorrência desse bioma (FERREIRA et al., 2012; IBAMA, 2013). Apesar de apresentarem solos com baixa fertilidade, estas florestas não mostram sintomas de deficiências nutricionais devido a decomposição do material orgânico decíduo durante o ano junto à absorção de elementos do solo pela vegetação (SILVA et. al., 2007).

A decomposição é um processo natural realizado principalmente por fungos e bactérias, no qual através deste processo são reciclados nutrientes presentes na composição de todos os seres vivos. Por isso, a decomposição é extremamente importante para o equilíbrio ecológico dos ecossistemas florestais (CERETTA et al., 2002), em especial de florestas urbanas, que apresentam baixa conexão com outras áreas florestadas. De acordo com Leitão-Filho (1993), os solos da Mata Atlântica são muito lixiviados, ácidos e distróficos, e pouco se conhece sobre a dinâmica de nutrientes que ocorre neste compartimento edáfico, derivado principalmente de rochas cristalinas pré-paleozóicas (granitos e gnaisses) e rochas sedimentares. Em geral, os solos são componentes frágeis do sistema e quando manejados de forma errada, o carbono orgânico pode ser mineralizado e jogado na atmosfera como $\mathrm{CO}_{2}$. Porém, quando o manejo ocorre de forma correta, o sistema pode sequestrar o $\mathrm{C}$ da atmosfera, tornando-se uma importante estratégia regional e global para compensar as emissões de $\mathrm{CO}_{2}$, proveniente da queima de combustíveis fósseis, atenuando assim algumas consequências das mudanças climáticas (SIGNOR, 2010).

O domínio de uma estratégia de ciclagem de nutrientes é importante nos programas de regeneração do bioma Mata Atlântica, uma vez que no Governo do Presidente Luís Inácio Lula da Silva foi assinado um decreto (Lei 11.428 de 22 de Dezembro de 2006) para aumentar a área de preservação da floresta de 7\% para 20\% (BRASIL, 2006). Por isso, torna-se necessário saber o nível nutricional do solo da floresta, bem como da serapilheira que o compõem, pois assim torna-se possível 


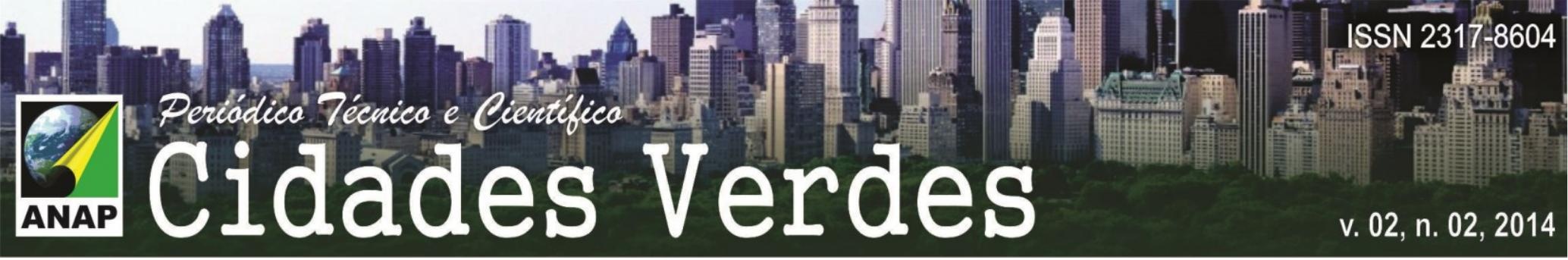

aplicar eficientemente políticas de preservação e reflorestamento, principalmente em florestas urbanas, local que ainda recebe pouca atenção por ecólogos florestais. Assim, o objetivo deste trabalho foi avaliar uma parte da ciclagem de nutrientes do solo de uma floresta urbana, especificamente no Parque Ecológico do Guarapiranga, localizado na cidade de São Paulo.

\section{MATERIAL E MÉTODOS}

\section{Área de estudo}

O Parque Ecológico do Guarapiranga, situado na zona sul do município de São Paulo, à margem do Reservatório do Guarapiranga (2341'50'S a 2343'33"S e 4644'39'W a 4647'09' $W$ ), foi criado pelo Decreto Estadual $n^{\circ} 30.442$ de 20 de setembro 1989 (BRASIL, 1989). Como está no Planalto Paulista, suas altitudes variam de $730 \mathrm{~m}$ a $830 \mathrm{~m}$. A precipitação na área varia de $1.300 \mathrm{~mm}$ a $1.900 \mathrm{~mm}$ anuais, com o clima típico de chuvas predominando nos meses de verão sendo o inverno mais seco. As temperaturas médias variam entre $16^{\circ} \mathrm{C}$ e $23^{\circ} \mathrm{C}$ e os ventos predominantes de SW-NE (LIEBERG, 2003). A vegetação tem a presença de árvores de médio porte, com aspecto intermediário de sucessão, formando uma floresta urbana fechada e densa. As árvores formam um microclima apropriado para as espécies desta mata, gerando sombra e umidade.

\section{Avaliação da serapilheira}

Para a quantificação da produção de serapilheira foram utilizados 40 coletores circulares com $55 \mathrm{~cm}$ de diâmetros cada um, confeccionados com tela de nylon $2 \mathrm{~mm}$ para ocorrer vazão de água, instalados a $50 \mathrm{~cm}$ do solo para não ter interferência de organismos decompositores. Os coletores foram distribuídos numa área previamente selecionada de $40 \times 100 \mathrm{~m}$. Entre os meses de abril e outubro de 2012, as coletas de serapilheira foram feitas mensalmente, tendo, portanto, sete coletas ao longo do experimento nas parcelas do Parque Ecológico do 
Guarapiranga. As amostras foram recolhidas e levadas ao laboratório para serem colocadas em estufa a $65^{\circ} \mathrm{C}$ por $72 \mathrm{~h}$ até alcançarem peso constante e em seguida pesadas, a fim de se obter a massa seca.

A avaliação da taxa de decomposição foi feita pela análise de perda de massa, utilizando sacos de decomposição (litter bags) que consistiam em sacolas de nylon com malha de $2 \mathrm{~mm}$, medindo $0,30 \times 0,30 \mathrm{~cm}$ respectivamente. Foram distribuídas 30 sacolas aleatoriamente na superfície do solo da floresta, simulando a queda natural do material formador da serapilheira, contendo 10 gramas de massa seca de serapilheira em cada saco de decomposição (FERNANDES et al., 2006; PEREIRA et al., 2008; MENEZES et al., 2010)

Os litter bags foram instalados durante o período com menor índice de precipitação do ano, ou seja, entre maio e outubro de 2012 e coletados 5 amostras a cada 30, 60, 90, 120 e 150 dias. Após a coleta, os litter bags foram lavados com água destilada em laboratório para retirar todo resíduo que pudesse interferir na correta interpretação dos dados químicos. Posteriormente o material foi seco em estufa de circulação de ar forçado a $65^{\circ} \mathrm{C}$ e obtida a sua massa seca em balança analítica de precisão de duas casas decimais.

Após a obtenção de massa seca, o material foi enviado ao laboratório de Análise de Solo e Planta da Universidade Estadual Paulista - UNESP (Unidade Jaboticabal), para a quantificação de macro e micronutrientes. Foi utilizado o método de digestão ácida nitroperclorica (ácido nítrico + ácido perclorico, 2:1) e mistura digestora de ácido sulfúrico + reagentes.

\section{Coleta das amostras de solo}

As coletas foram realizadas no mês de julho de 2013. Foram feitas 3 trincheiras de $2 \mathrm{~m} \times 2 \mathrm{~m}$, onde foram coletadas amostras em 3 profundidades distintas, sendo elas de 0-10 cm, 10-20 cm e 20-30 cm (MARTINS, 2010). Tais trincheiras foram marcadas com barbante e as perfurações foram feitas com o auxilio de uma cavadeira. O material edáfico foi seco ao sol e separado de matérias vegetais e pedras. Em seguida o material foi peneirado em malha de $2 \mathrm{~mm}$ e separados em sacos plásticos transparentes (BERNOUX et al., 1999). 


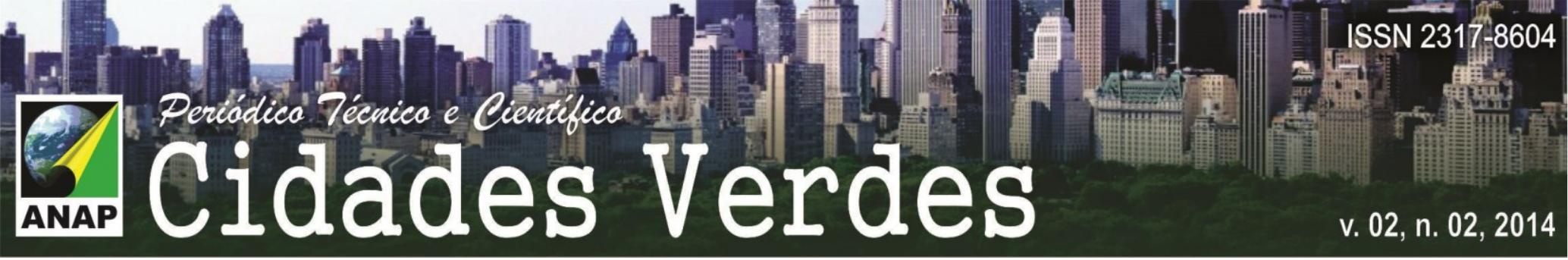

Posteriormente as amostras foram enviadas para o Laboratório Agrotécnico de Piracicaba (PIRASOLO) e analisadas quimicamente quanto aos elementos carbono, nitrogênio e fósforo.

Este projeto teve a aprovação da Comissão Técnica Científica - COTEC (Instituto Florestal) processo: 260108-007.044/2012, seguindo desta forma, as normas da lei e os padrões éticos da pesquisa científica.

\section{Análises Estatísticas}

Análises de correlação de Spearman foram feitas para se encontrar os possíveis fatores climáticos que mais influenciaram a decomposição da serapilheira. Para se observar diferenças dos elementos ao longo do perfil de profundidade do solo aplicou-se o teste de Kruskal-Wallis.

\section{RESULTADOS E DISCUSSÃO}

\section{Produção e decomposição da serapilheira}

A produção de serapilheira ocorreu durante todo o período de estudo e apresentou importante variação entre os meses. A sua produção um ano de estudo foi de 5,6 Mg.ha ${ }^{-1}$, sendo que a maior e a menor produção foram verificadas em dezembro e agosto (862 Kg.ha ${ }^{-1}$ e $259 \mathrm{Kg} \mathrm{ha}^{-1}$, respectivamente), conforme mostra a figura 1. O mês de agosto apresentou a menor produção do material decíduo ao longo do experimento indicando que as espécies provavelmente não sofreram um estresse com a diminuição dos índices pluviométricos, caracterizados por serem baixos nesta época do ano na região (FERREIRA, 2007). O aumento do material decíduo a partir do mês de setembro era esperado, pois se trata do mês que se inicia a estão de chuvas na cidade de São Paulo. Gomes et al. (2006) encontrou resultados semelhantes ao deste estudo ao constatar maior produção de serapilheira no final da estação seca e início da estação chuvosa no Rio de Janeiro.

Estes resultados sugerem uma renovação do folhedo das árvores nesta época do ano, uma vez que Vidal et al. (2007) mostraram que numa floresta 
secundária na região sudeste do Brasil, próximo a cidade de São Paulo, ocorreu maior produção de serapilheira a partir de setembro, sendo que a produção se manteve alta durante toda a primavera. Paula et al. (2009) durante o experimento realizado numa floresta na Ilha de Marambaia, RJ, evidenciaram que o maior aporte ocorreu nos meses chuvosos. Menezes et al. (2010) observaram que houve o mesmo padrão ao deste estudo em relação à deposição de material decíduo, no qual evidencia uma maior quantidade de serapilheira aportada no período que compreende o final da estação seca e início da estação chuvosa. Cabe ressaltar que esta tendência é quebrada em outras Florestas Ombrófilas Densas, como no caso da Amazônia. Brando et al., (2008) mostraram um padrão de produção de serapilheira mais pronunciado durante a estação seca, o que provavelmente compreende uma estratégia de defesa contra a perda de água.

A)

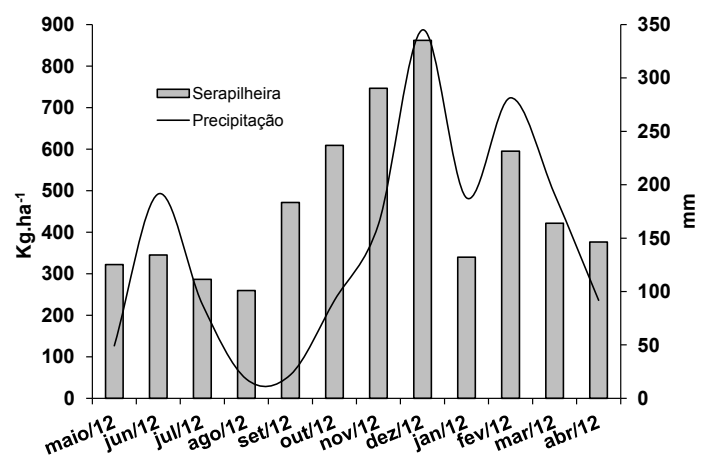

B)

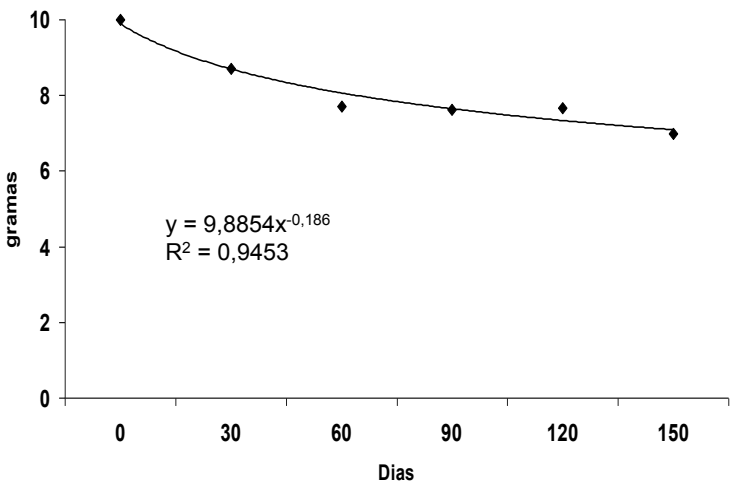

Figura 1 - Produção e decomposição de serapilheira. Em A) produção em Kg.ha-1, e em B) decomposição do material decíduo ao longo do estudo no Parque Ecológico do Guarapiranga, SP.

Os litter bags foram colocados no campo com $10 \mathrm{~g}$ de massa seca de serapilheira cada um. A primeira coleta ocorreu 30 dias após a inserção dos sacos decompositores na floresta. Na figura 2, são apresentados os valores de perda de massa seca da serapilheira durante o período de avaliação, na qual se observou no primeiro mês, uma perda de massa de aproximadamente 18\%. Essa curva apresentou uma tendência potencial de decaimento $\left(R^{2}=0,9453\right)$ tendo perdido no final do experimento $24,8 \%$ da massa inicial. Em outro tipo de fragmento florestal, Paula et al. (2009) encontraram forte correlação entre a taxa de decomposição com a precipitação para todas as áreas abordadas, sendo necessários pelo menos 150 dias para notar que menos de $40 \%$ havia sido decomposto da quantidade inicial 


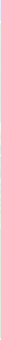

condicionada por eles. Em geral, este processo de decomposição está intimamente ligado as condições naturais de temperaturas, chuva, vento ou qualquer outra contribuição ecológica do ambiente físico, sendo que condições atípicas podem ter efeito depressor sobre a decomposição, resultando na velocidade com que ocorre (DELITTI, 1995).

Os mesmos fatores ambientais observados na produção de serapilheira foram considerados na parcela de decomposição, sendo estes, temperatura, vento, umidade relativa do ar, precipitação e radiação solar global. A análise de correlação de Spearman mostrou algumas relações entre variáveis ambientais e a taxa de decomposição, dentre as quais se destacaram a umidade relativa do ar $(r=0,40)$ e velocidade de vento $(r=-0,41)$. Estes resultados podem sugerir uma dependência da atividade decompositora com uma maior disponibilidade hídrica no local, aumentando assim a eficiência metabólica deste grupo ecológico. Segundo Tauk (1990), a decomposição pode ser definida por perda de massa, na qual ocorre rápida decomposição inicial, mas posteriormente ela passa a ocorrer num processo mais lento, conforme os resultados deste experimento. Essa lentidão pode ocorrer devido ao mecanismo de absorção e a queda da taxa de biomassa no solo, sendo este um processo complexo e dependente de inúmeros fatores, ao passo que um deles envolve uma extensa variedade de microrganismos decompositores.

A fração folha representa um importante habitat para fungos decompositores e nesta fração estão presentes inúmeras espécies capazes de decompor o material decíduo. No entanto, fatores ambientais, como por exemplo, temperatura e umidade, exercem forte influência sob as atividades decompositoras (GRANDI e GUSMÃO 2002; MARQUES et al., 2008). Outros autores também abordam de maneira clara que fatores ambientais atuam sobre os microrganismos decompositores (SOUZANETO et al., 2011). Santos et. al. (2009) num estudo destinado a decomposição e liberação de nitrogênio em época de seca evidenciaram que a baixa precipitação durante o período de experimento contribuiu para uma decomposição mais lenta e tardia das leguminosas estudadas. É importante ressaltar que este experimento ocorreu durante a estação com menores temperaturas e índices pluviométricos do ano, sendo que este quadro pode ser diferente nas estações de primavera e verão. 
Assim, estes resultados mostram que o funcionamento de ciclagem de nutrientes via decomposição em florestas urbanas se assemelham às demais formações florestais.

\section{Análise química da serapilheira}

A tabela 1 apresenta as concentrações médias de macro e micronutrientes na serapilheira em seus respectivos meses de experimento. A maior parte dos nutrientes não manteve um padrão médio em sua produção. A concentração de nitrogênio foi maior nos meses de junho e julho e sua menor quantidade em maio. $A$ quantidade de fósforo se manteve estável durante todo o experimento. Para o potássio, foram quantificados valores mais elevados em agosto e setembro. Quanto aos micronutrientes, o elemento ferro apresentou importante diferenciação durante o período, apresentando uma menor concentração do metal durante o mês de maio e alta quantidade do elemento no mês de setembro $(187,0 \mathrm{mg} / \mathrm{kg}$ e 369,5 mg/kg, respectivamente). Com o mesmo parâmetro de comparação o elemento manganês apresentou as maiores taxas em abril e menores em maio. Os demais elementos apresentaram pouca diferenciação durante o período estudado.

Tabela 1 - Concentrações médias de macro e micronutrientes de serapilheira produzidos durante o experimento. Macronutrientes ( $\mathrm{N}, \mathrm{P}, \mathrm{K}, \mathrm{Ca}, \mathrm{Mg}, \mathrm{S}$ ) em g/kg. Micronutrientes ( $\mathrm{B}, \mathrm{Cu}, \mathrm{Fe}, \mathrm{Mn}, \mathrm{Zn}$ ) em $\mathrm{mg} / \mathrm{kg}$

\begin{tabular}{|c|c|c|c|c|c|c|c|c|c|c|c|c|c|c|}
\hline & \multicolumn{11}{|c|}{ Produção } & \multicolumn{3}{|c|}{ Decomposição } \\
\hline & $\mathbf{N}$ & $\mathbf{P}$ & $\mathrm{K}$ & $\mathrm{Ca}$ & $\mathbf{M g}$ & $S$ & B & $\mathrm{Cu}$ & $\mathrm{Fe}$ & $M n$ & $\mathrm{Zn}$ & $\mathbf{N}$ & $\mathbf{P}$ & $\mathbf{K}$ \\
\hline & ......... & $\ldots \ldots .$. & $. . \mathrm{g} / \mathrm{Kg}$ & $\ldots \ldots$ & $\ldots \ldots . .$. & & ..... & .......... & $\mathrm{mg} / \mathrm{Kg}$ & ... & $\ldots$ & $\ldots \ldots .$. & $g / K$ & 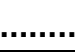 \\
\hline ABR & 17,8 & 0,7 & 5,2 & 13,7 & 3,1 & 1,9 & 38,5 & 14,5 & 295,0 & 1232,0 & 45,5 & \# & \# & \# \\
\hline MAI & 15,7 & 0,7 & 5,2 & 11,8 & 3,0 & 1,9 & 28,0 & 11,0 & 187,0 & 954,5 & 33,5 & 15,7 & 0,7 & 5,2 \\
\hline JUN & 18,0 & 0,7 & 6,2 & 12,0 & 2,7 & 1,9 & 31,0 & 18,0 & 229,5 & 1071,5 & 48,0 & 17,6 & 0,5 & 2,1 \\
\hline JUL & 18,9 & 0,7 & 6,5 & 12,8 & 3,1 & 2,0 & 40,0 & 17,5 & 264,5 & 1155,5 & 62,0 & 20,4 & 0,5 & 1 \\
\hline AGO & 16,9 & 0,7 & 10,9 & 12,1 & 2,9 & 2,6 & 41,5 & 18,0 & 217,5 & 1074,0 & 74,0 & 19,3 & 0,5 & 1,4 \\
\hline SET & 16,9 & 0,7 & 9,8 & 13,3 & 2,9 & 2,6 & 40,5 & 16,0 & 369,5 & 1129,0 & 76,5 & 21 & 0,5 & 0,7 \\
\hline
\end{tabular}

Por se tratar de um elemento extremamente importante para a biosfera, algumas formas de vida possuem habilidades específicas para a utilização do nitrogênio, dentre as quais pode-se citar o caso de diversas plantas no processo de translocação de nitrogênio antes da senescência foliar, fato que pode ser refletido numa menor devolução via serapilheira. Os valores encontrados neste estudo estão 
de acordo com os de outros autores em regiões tropicais (SCHUMACHER et al., 2003; CUNHA, 1997), o que valida os resultados encontrados em florestas urbanas. Gomes et al. (2006) e Bizuti (2011), mensuraram as frações de serapilheira produzida em uma área de arvoredo na região de Mogi-Guaçu, SP, e mostraram que os padrões de deposição do fósforo incidiram em maior quantidade nas partes reprodutivas encontradas, que embora possuam altas concentrações de alguns nutrientes, a baixa fitomassa pouco contribuiu para o retorno desses elementos ao solo. Em geral, os macro e micronutrientes se comportaram sem grandes variações ao longo do período de estudo, evidenciando uma distribuição normal ao longo do ano.

De acordo com a tabela 1, verificou-se que o nitrogênio não apresentou um padrão decrescente na devolução do elemento para o solo da floresta urbana. Estes resultados podem ser explicados pela diferente constituição do material dos litter bags e também pela mobilização deste elemento na planta mãe antes da senescência do órgão.

A dinâmica de transferência de nitrogênio da serapilheira em decomposição para o ambiente apresentou padrões diferentes do que outros estudos. Por se tratar de uma floresta secundária que pode ter uma considerável quantidade de plantas leguminosas, o nitrogênio não sofreu decaimento constante, sendo que este fenômeno pode ser explicado pela possível concentração de polifenóis, que segundo Costa et al (2008), pode agir negativamente na velocidade da decomposição da serapilheira, pois esta substância tem a capacidade de inibir a fixação biológica do nitrogênio.

O fósforo apresentou um valor relativamente constante em sua liberação para o ambiente, tendo maior perda do primeiro mês para o segundo. Por se tratar de um elemento muito reativo e que raramente possui um estágio gasoso em seu ciclo, os íons fosfatos podem ter sido lixiviados rapidamente no sistema. Em sistemas oligotróficos a disponibilidade do $\mathrm{P}$ na serapilheira é menor, devido à falta de nutrientes disponíveis no solo. Por se tratar de num fragmento de mata secundária da Floresta Atlântica, pode-se assumir que o sistema não seja favorável para um desperdício do elemento, sendo reaproveitado rapidamente pelas plantas, estando assim, em baixos índices no material decíduo. 
O potássio foi o elemento que melhor explicou a atividade decompositora, pois apresentou uma grande perda nos meses iniciais diminuindo a sua liberação com o passar do tempo, fato que pode ser explicado pela fácil mineralização por ele não fazer parte dos componentes estruturais dos tecidos orgânicos (PEREIRA, 2008), sendo que pode ser atribuído ao potássio um alto poder de lixiviação.

\section{Macronutrientes do solo}

A análise química do solo do Parque Ecológico do Guarapiranga mostrou que houve disponibilidade maior dos três elementos analisados ( $C, N$ e $P$ ) na camada superior do solo $(0-10 \mathrm{~cm})$. Isso indica que há uma influência direta da serapilheira presente no solo desta floresta ofertando maior quantidade destes elementos para o compartimento edáfico, para posterior decomposição e absorção pela vegetação (ROSCOE; MACHADO, 2002). Araújo et al. (2006), também constatou com seu trabalho, que na região mais superficial do solo, onde a serapilheira está depositada há uma quantidade muito maior de nutrientes disponíveis para absorção pelas plantas. O elemento carbono apresentou variação em sua quantidade ao longo do perfil do solo, sendo que de $0-10 \mathrm{~cm}$ de profundidade foram encontrados $24,3 \mathrm{~g} . \mathrm{dm}^{-}$ 3. de 10-20 cm foram encontrados $21,3 \mathrm{~g} \cdot \mathrm{dm}^{-3}$; e de $20-30 \mathrm{~cm}$ foram encontrados 20 g. $\mathrm{dm}^{-3}$. Nesta análise não houve diferença significativa entre os níveis de profundidade (Figura 2).

O carbono é o constituinte principal da MOS, sendo assim, há a influência direta desta no estoque desse elemento no solo (SANTOS, 2007). O estoque desse elemento no solo está relacionado a vários fatores, sendo eles aspectos geológicos, vegetação local, mudanças climáticas, a fauna local e a forma como esse solo é usado pelo homem (TRUMBORE; CAMARGO, 2009). Sugere-se que este solo apresenta uma grande quantidade de MO (matéria orgânica) depositada, o que implica numa alta capacidade de troca catiônica. Martins (2010) encontrou valores semelhantes aos deste trabalho, já que ambos foram realizados em floresta ombrófila densa, onde há maior concentração de árvores e consequentemente maior deposição de serapilheira no solo, gerando um aumento na quantidade de carbono neste compartimento. 


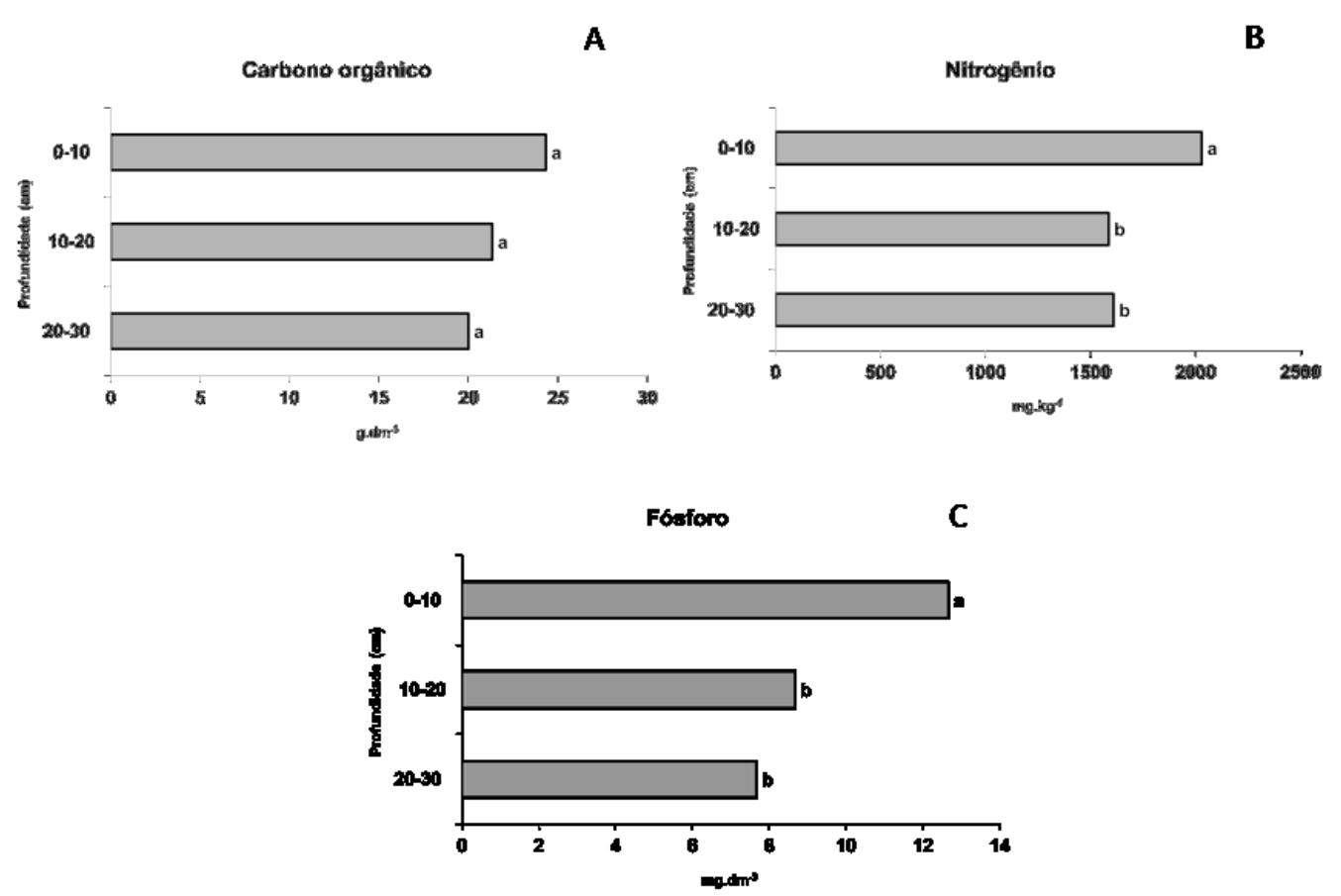

Figura 2. Teores de carbono orgânico (figura A), Nitrogênio (figura B) e Fósforo (figura C) presentes no solo do Parque do Guarapiranga.

Assim como para o carbono, nas camadas mais profundas se observou uma baixa significativa dos conteúdos de fósforo e nitrogênio. Com isso, pode-se dizer que estes elementos estão concentrados livres, em sua maior parte na camada da manta orgânica, também conhecida como horizonte O. Esses elementos são caros na natureza e apresentam extrema importância na construção de biomoléculas vitais, tais como proteínas e ácido nucléico (D'ANDRÉA et al., 2004).

\section{Relações C:N, C:P e N:P}

A análise de solo desse estudo, apresentou a relação $\mathrm{C}: \mathrm{N}$ mais alta na camada $10-20 \mathrm{~cm}$ de profundidade, indicando decomposição lenta neste estrato do compartimento edáfico (WSNIEWSKJ; HQLTZ, 1997). Martins (2010) relatou a relação C:N está diretamente ligada a ação da microbiota presente no solo, o que pode explicar a diminuição desses elementos ao longo do aumento da profundidade. Porém, neste trabalho optou-se em quantificar apenas tais elementos do solo, não se expandindo a comunidade microbiológica (SANDI, 2009). A relação C:P aumentou ao longo do perfil do solo, sugerindo então que a taxa de decomposição 
no local esteja alta, pois a ciclagem desses elementos parece ocorrer de forma rápida. Esta evidência é previsível para florestas secundárias que se encontram em estágios iniciais de regeneração. Pavinato e Rosolem (2008) perceberam que na medida em que há mais carbono e fósforo disponíveis no solo, maior é a taxa de decomposição, sendo assim, à medida que há a absorção destes compostos orgânicos há também um aumento na relação C:P (Figura 3).

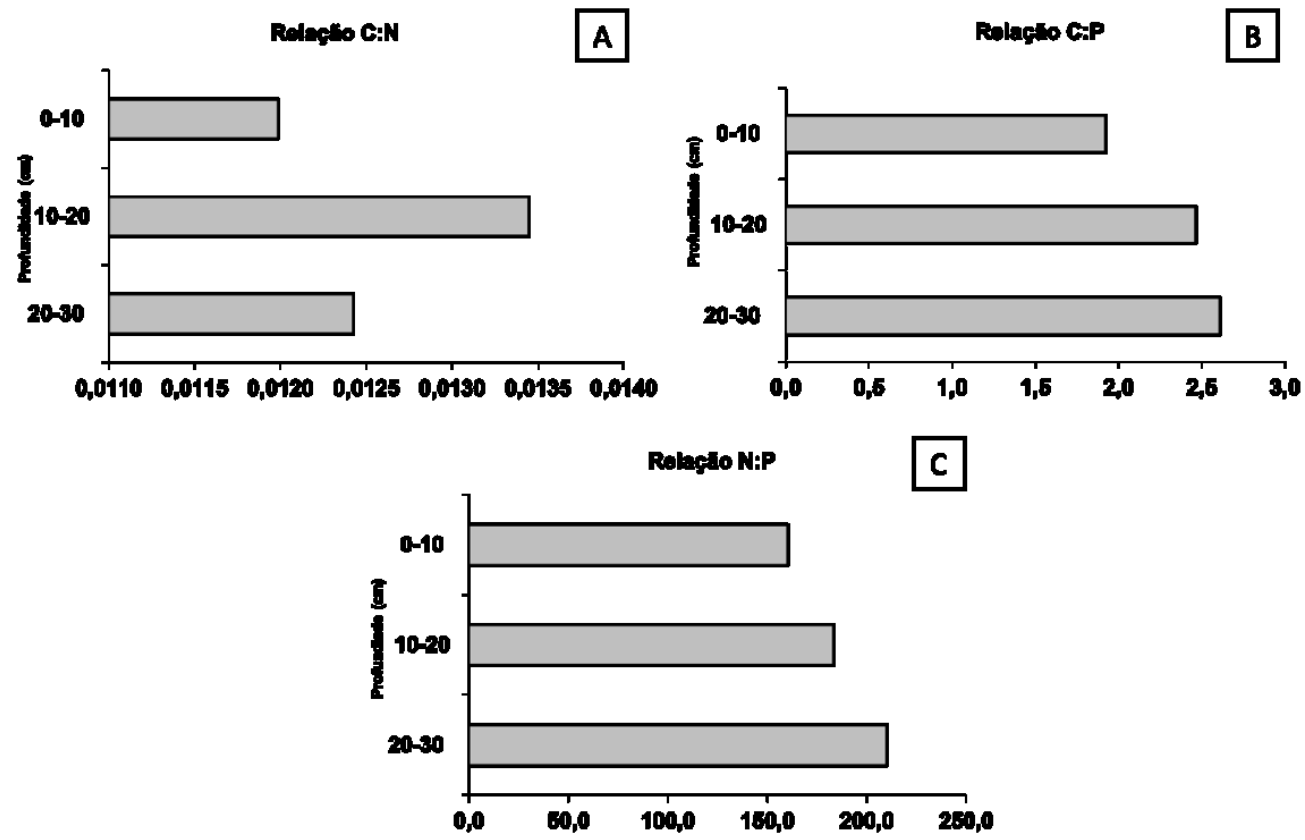

Figura 3. Gráfico da relação entre os nutrientes. Em A- relação C:N, em B - relação C:P e em C relação N:P, no solo do Parque do Guarapiranga.

Já para a relação N:P observou-se no solo do Parque do Guarapiranga um aumento equilibrado e uniforme, indicando baixa disponibilidade destes elementos, fato que indica, para esta relação, uma taxa de decomposição mais lenta ao longo deste perfil analisado. De acordo com Lima (2005) o baixo teor desses nutrientes, pode ser explicado por um conjunto de mecanismos realizados pela planta para uma menor perda desses nutrientes para o ambiente, já que são caros de se adquirirem. Dentre esses mecanismos está a proficiência de reaproveitamento de nutrientes, que consiste na concentração mínima de nitrogênio ou fósforo nas folhas senescentes, gerando uma diminuição na perda desses nutrientes para o ambiente. 


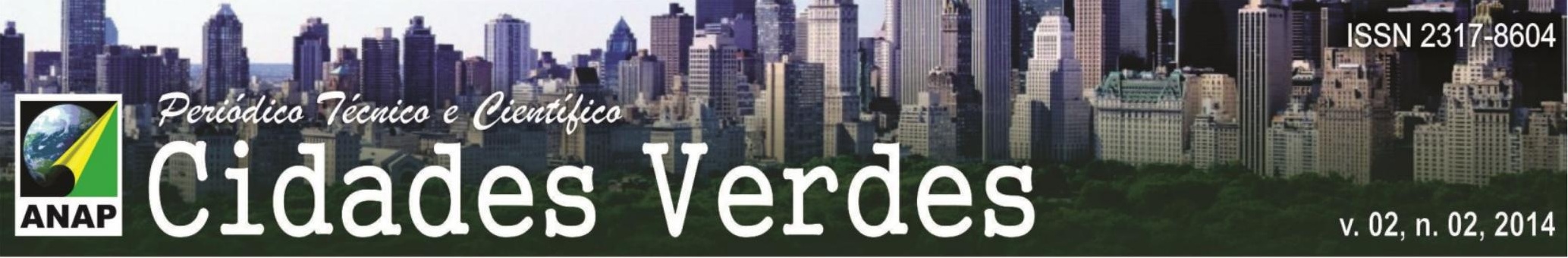

CASTRO, J.C. Carbono orgânico nas frações granulométricas e húmicas em solos de diferentes texturas sobre floresta da região noroeste mato-grossense. 2008. 46 p. Dissertação (Pós - graduação) - Programa de Pós - Graduação em Ciências Florestais e Ambiental - Faculdade de Engenharia Florestal. Universidade Federal do Mato Grosso, Cuiabá, 2008.

CERETTA, C.A.; et al. Produção e decomposição de fitomassa de plantas invernais de cobertura de solo de milho, sob diferentes manejos da adubação nitrogenada. Ciência Rural, Santa Maria, v. 32, n. 1, 2002.

COSTA, G. S.; et al. Aporte de nutrientes pela serapilheira em uma área degradada e revegetada com leguminosas arbóreas. Revista Brasileira de Ciência do Solo. Viçosa, v.28. n.5. p. 917927.2004 .

CUNHA, G. C. Aspectos da ciclagem de nutrientes em diferentes fases sucessionais de uma floresta estacional do Rio Grande do Sul. Piracicaba, 1997. 130 p. Dissertação (Mestrado em Ecologia). Universidade de São Paulo Escola Superior de Agricultura "Luiz de Queiroz". 1997.

D'ANDRÉA, A.F.; et al. Estoque de carbono e nitrogênio e formas de nitrogênio mineral em um solo submetido a diferentes sistemas de manejo. Pesquisa Agropecuária Brasileira, Brasília, v.39, n.2, p.179-186, 2004

DELITTI, W. B. C. Estudos de ciclagem de nutrientes: instrumentos para a análise funcional de ecossistemas terrestres. Oecologia Brasiliensis, Rio de Janeiro, v. 1, p. 469-486, 1995.

FERNANDES, M. M.; PEREIRA, M. G.; MAGALHÃES, L. M. S.; CRUZ, A. R.; GIACOMO, R. G. Aporte e decomposição de serapilheira em áreas de floresta secundária, plantio de sabiá (Mimosa caesalpiniaefolia Benth) e andiroba (Carapa guianensis Aubl) na flona Mário Xavier, RJ. Ciência Florestal, Santa Maria, v. 16, n.2, p. 163-175, 2006.

FERREIRA, M. L. Relações entre antioxidantes e sintomas visíveis bioindicadores de ozônio atmosférico e as defesas antioxidantes em Ipomea nil cv. Scarlat $O$ Hara sob efeito da poluição aérea urbana de São Paulo. São Paulo, 2007. Dissertação (Mestrado em Biodiversidade Vegetal e Meio Ambiente) -Instituto de Botânica, 2007.

FERREIRA, M. L.; ESPOSITO, J. B. N.; SOUZA, S. R.; DOMINGOS, M. Critical analysis of the potential of Ipomoea nil 'Scarlet $\mathrm{O}$ Hara' for ozone biomonitoring in the sub-tropics. Journal of Environmental Monitoring, v. 12, p. 2-35, 2012.

GOMES, S. R., et al. Produção de serapilheira e retorno de nutrientes ao solo em arboreto depaubrasil (Caesalpinia echinata Lam.) em Mogi-Guaçu, São Paulo, Brasil. Hoehnea, São Paulo, v. 33, n. 3, p. 339-347, 2006.

GRANDI, R. A. P.; GUSMÃO, L. F. P. Hyphomycetes decompositores do folhedo de Tibouchina pulchra Cogn. Revista Brasileira de Botânica, São Paulo, v. 25, n. 1, p. 79-87, mar 2002.

IBAMA - Instituto Brasileiro do Meio Ambiente. Ecossistemas brasileiros. Mata Attântica. Brasília, 2013. Disponível em (http://www.ibama.gov.br/ecossistemas/mata atlantica.htm). Acesso em 21/05/2013.

LEITÃO-FILHO, H. F. Ecologia da Mata Atlântica em Cubatão, sp. Campinas: Editora da UNIFESP; Editora da UNICAMP, 1993. 184p.

LIEBERG, S. A. Análise sucessional de fragmentos florestais urbanos e delimitações de trilhas como instrumento de gestão e manejo no programa de uso público do Parque Ecológico do Guarapiranga, Rio Claro, 2003. 117p. Dissertação (Doutorado) - Instituto de Biociências da Universidade Estadual Paulista “Julio de Mesquita Filho" São Paulo, 2003. 


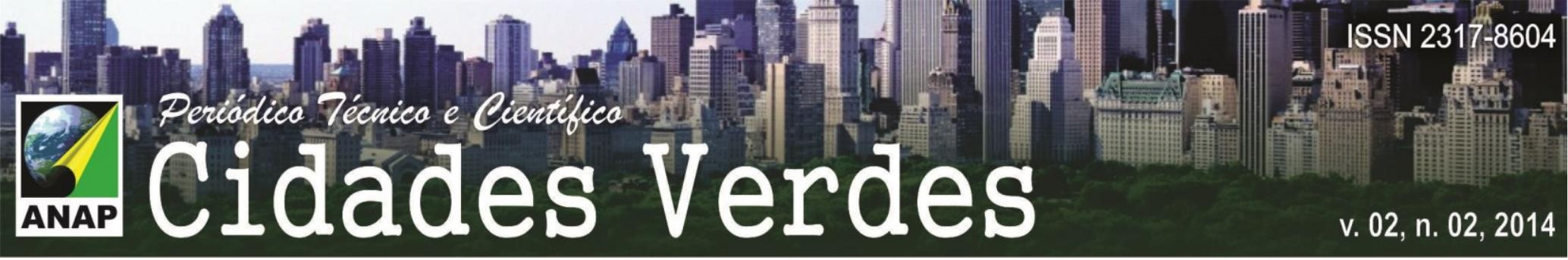

LIMA, A. L. S. Relação entre longevidade foliar, nitrogênio e compostos secundários em folhas de leguminosas arbóreas, Campinas, 2005. Tese (Doutorado) - Instituto de Biologia, Universidade Estadual de Campinas, 2005.

MARQUES, M. F. O.; et al. Riqueza de espécies de fungos conidiais em duas áreas de Mata Atlântica no Morro da Pioneira, Serra da Jibóia, BA. Acta Botanica Brasilica, Bahia, v. 22, n. 4, p 954-961, jan 2008.

MARTINS, S. C. Caracterização dos solos e serapilheira ao longo do gradiente altitudinal da Mata Atlântica, estado de São Paulo. Piracicaba, 2010. 155 p. Tese (Doutorado) - Centro de Energia Nuclear na Agricultura, Universidade de São Paulo, 2010.

MARZLUFF, J. M. 2001. Worldwide urbanization and its effects on birds. Pages 19-47 in Marzluff JM, Bowman R, Donnelly R, eds. Avian Ecology in an Urbanizing World. Norwell (MA): Kluwer.

MENEZES, C. E. G; et al. Aporte e decomposição da serapilheira e produção de biomassa radicular em florestas com diferentes estágios sucessionais em Pinheiral, RJ. Ciência Florestal, Santa Maria, v 20, n. 3, p. 439-452, jul/ set. 2010.

OLIVEIRA, K. C.; BENCHIMOL, J. F.; LAMANO-FERREIRA, A. P. N. Áreas Verdes Urbanas: Percepção De Frequentadores Em Relação À Praça Roosevelt Revitalizada No Município De São Paulo, SP. In: Encontro Internacional sobre Gestão Empresarial e Meio Ambiente - ENGEMA, 2013, São Paulo. Ética e sustentabilidade socioambietnal na empresa inovadora, 2013.

PAULA, R. R.; et al. Aporte de nutrientes e decomposição da serapilheira em três fragmentos florestais periodicamente inundados na ilha da Marambaia, RJ. Ciência Florestal, Santa Maria, v. 19, n.2, p. 139-148, 2009.

PEREIRA, M.G.; et al. Aporte e decomposição da serapilheira na floresta atlântica, ilha da Marambaia, Mangaratiba, RJ. Ciência Florestal, Santa Maria, v.18, n.4, p.443-454, 2008.

Pickett, S. T. A.; Cadenasso, M. L.; Grove, J. M.; Nilon, C. H.; Pouyat, R. V.; Zipperer, W. C.; Costanza, R. URBAN ECOLOGICAL SYSTEMS: Linking Terrestrial Ecological, Physical, and Socioeconomic Components of Metropolitan Areas. Annual Review of Ecology and Systematics, v. 32, p. 127-157, 2001.

RIBEIRO, M. C.; METZGER, J. P.; MARTENSEN, A. C.; PONZONI, F. J.; HIROTA, M. M. The Brazilian Atlantic Forest: How much is left, and how is the remaining forest distributed? Implications for conservation. Biological Conservation, v. 142, p. 11411153, 2009.

ROSCOE, R.; MACHADO, P. L. O. A. Fracionamento físico do solo em estudos da matéria orgânica, Dourados. Embrapa Agropecuária Oeste, Brasilia, p.86, 2002.

SANDI, J. T. T. Estoque de carbono no solo sob diferentes coberturas vegetais, Chapecó - SC. Dissertação (Pós-Graduação) - Programa de Pós-Graduação em Ciências Ambientais - Universidade Comunitária da Região de Chapecó, 2009.

SANTOS, R.; et al. Decomposição e liberação de nitrogênio de duas espécies de adubos verdes manejados no período seco em cafezal. Revista Brasileira de Agroecologia, Cruz Alta, v. 4, n. 2, p. 1342- 1345, nov 2009.

SANTOS, E. Carbono, nitrogênio e relação $\mathrm{C} / \mathrm{N}$ em gleissolo e cambissolo sob diferentes tipologias vegetais na área de ocorrência da floresta ombrófila densa, Antonina - PR, Curitiba. Dissertação (Pós-Graduação) - Programa de Pós- 


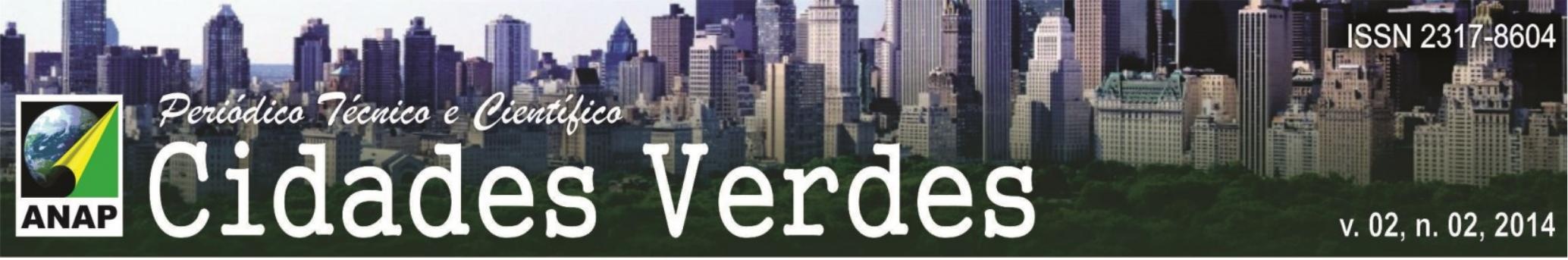

Graduação em Ciência do Solo, Setor de Ciências Agrárias - Universidade Federal do Paraná, 2007.

SCHUMACHER, M.V., et al. Retorno de nutrientes via deposição de serapilheira em um povoamento de Acacia-Negra (Acacia mearnsii De Wild.) no estado do Rio Grande do Sul. Revista Árvore, Viçosa, v.22, n. 4, p. 791-798, 2003.

SIGNOR, D. Estoques de carbono e nitrogênio e emissões de gases do efeito estufa em áreas de cana-de-açúcar na região de Piracicaba. Piracicaba, 2010. 119 p. Tese (Mestrado) - Escola Superior de Agricultura "Luiz de Queiroz", Universidade de São Paulo, 2010.

SILVA, R. C.; et al. Alterações nas propriedades químicas e físicas de um Chernossolo com diferentes coberturas vegetais. Revista Brasileira de Ciência do Solo, Viçosa, v. 31, p. 101-107, 2007.

SOUZA NETO, E. N.; et al. Soil-atmosphere exchange of nitrous oxide, methane and carbon dioxide in a gradient of elevation in the coastal Brazilian Atlantic Forest. Biogeosciences, 8: 733-742, 2011.

TAUK, S. M. Biodegradação de resíduos orgânicos no solo. Revista Brasileira de Geociência, São Paulo, v. 20 n. 1, p 299-301, mar/dez 1990.

TRUMBORE, S.; CAMARGO, P. B. Dinâmica do carbono no solo. In: Michael Keller, Mercedes Bustamonte, John Gash e Pedro Silva Dias. (Org.). Amazonia and Global Change. 1ed.: Geophysical Monograph Series, Washington DC, v. 186, 2009.

WSNIEWSKJ, C.; HQLTZ, G. P. Decomposição da palhada e liberação de nitrogênio e fósforo numa rotação aveia-soja sob plantio direto. Pesquisa Agropecuária Brasileira, Brasília, v.32, n.11, p.1191-1197, 1997.

VIDAL, M. M.; et al. Produção de serapilheira em floresta Atlântica secundária numa paisagem fragmentada (Ibiúna, SP): importância da borda e tamanho dos fragmentos. Revista Brasileira de Botânica, São Paulo, v. 30, n. 3, p. 521-532, jul/set. 2007. 